\title{
Are Emotions Embodied Evaluative Attitudes? Critical Review of Julien A. Deonna and Fabrice Teroni's The Emotions: A Philosophical Introduction
}

\author{
Joel Smith \\ University of Manchester \\ BIBLID [0873-626X (2014) 38; pp. 93-106]
}

\begin{abstract}
Deonna and Teroni's The Emotions is both an excellent introduction to philosophical work on emotions and a novel defence of their own Attitudinal Theory. After summarising their discussion of the literature I describe and evaluate their positive view. I challenge their theory on three fronts: their claim that emotions are a form of bodily awareness, their account of what makes an emotion correct, and their account of what justifies an emotion.
\end{abstract}

\section{Keywords}

Emotion, embodiment, evaluation, correctness, justification

Deonna and Teroni's The Emotions is both an introduction and an original contribution in its own right. Presupposing no knowledge of philosophical work on the emotions, the book guides us through the central theories, discussing familiar issues and offering novel critical evaluation in equal measure. The book is a pleasure to read and is an ideal work to use in a postgraduate or final year undergraduate course on emotion. Indeed, I have used it in just this way twice. At the book's core, however, is an original theory of emotion, the "Attitudinal Theory". Whilst this account, and the book more generally, stands firmly within the philosophy of mind, the significant atten-

Disputatio, Vol. VI, No. 38, May 2014

Received: 31/03/2013 Accepted: 08/04/2014 
tion devoted to the relation between emotion and evaluation (and value itself) ensure that it will be of interest to those concerned with normative issues and the nature of our engagement with them. This neatly reflects the fact that one of the things that makes the philosophy of emotion such a fascinating area is that it stands at the intersection of the philosophy of mind and ethics. The emotions are that part of our psychological life through which we are most personally engaged with value, with what matters to us. It is a virtue of Deonna and Teroni's fantastic book that it paints such a vivid and recognisable picture of the nature and significance of this engagement.

In what follows I first outline a few of the book's central themes and arguments, subsequently turning to the Attitudinal Theory, Deonna and Teroni's positive account of emotion, subjecting it to a somewhat more detailed scrutiny. As will be seen, there are a number of objections that can be raised.

Emotions, Deonna and Teroni tell us in their opening chapter, are intentionally directed, phenomenal episodes that are to be distinguished from emotional dispositions (and sentiments, moods and character traits); and are evaluated for correctness, justification and propriety. A word about some of these is in order.

Intentionality. Since, when I am angry, I am angry at something or with someone, my anger exhibits intentionality. And as it is with anger, so it is with other emotions. We can then agree that emotions have content, or are meaningful. This is not to say that emotions have propositional content, although it does not rule it out, but simply to insist that they are directed toward things, their "particular objects". This, however, is not the end of the matter. For, as Deonna and Teroni tell us in Chapter 4, emotions possess "formal objects" (Kenny 1963: Chapter 9). These are evaluative properties that serve, amongst other things, to individuate the emotions. Thus by Deonna and Teroni's reckoning, fear is, in some way yet to be determined, associated with something's threatening me; anger with its offending me; shame with its degrading me; and so on. The most natural thought in this area, but hardly yet a theory, is that fearing $a$ involves taking $a$ to be threatening, being angry with $a$ involves 
taking $a$ to be offensive, and so on. Thus, the emotion ascribes the formal object to the particular object.

Phenomenality. There is, as philosophers are keen to say, something it is like to have an emotion. Joy, fear, resentment and pride feel a certain way. As such, they are episodic rather than dispositional phenomena. Conscious psychological episodes are the sorts of thing that populate the stream of consciousness. They include thoughts, imaginings, sensations, urges, judgements and, according to Deonna and Teroni, emotions. Psychological dispositions, on the other hand, are not themselves phenomenal but rather help to determine which conscious episodes one enjoys. So characterised, we might include beliefs, desires, sentiments and emotional dispositions among their number. A belief is itself not a phenomenal state but a person that believes that $P$ is thereby disposed to judge that $P$ in suitable circumstances. To see the distinction between emotional episodes and emotional dispositions, consider that I may for some time have been horrified by Dr. Frankenstein's creation but only upon seeing the creature feel fear.

Evaluation. Emotions can be correct or incorrect, justified or unjustified, appropriate or inappropriate. If I fear a harmless spider, my emotion is incorrect. Nevertheless, if the creature looks just like a dangerous one, my fear may still be justified. If I become angry with someone who has offended me, my emotion is correct. It may be, however, that my anger is the result of my bad mood, a factor that Deonna and Teroni take to undermine the possibility of its being justified. So correctness and justification are doubly dissociable. In addition, we also evaluate emotions for various sorts of appropriateness. Confronted by a pack of wolves, fear may be the least (prudentially) appropriate response despite, indeed because of, the threat they pose. Finding amusement at another's intense embarrassment may be (morally) inappropriate, no matter how funny their faux pas.

After briefly defending the coherence of the concept of emotion from recent scepticism (Chapter 2) ${ }^{1}$, Deonna and Teroni go on reject

\footnotetext{
${ }^{1}$ Unaccompanied chapter and page references are to Deonna and Teroni
} 
a number of views that attempt to reduce emotions to other, presumably better understood, psychological phenomena. For example, they reject the views that emotions are: beliefs or judgements about the non-evaluative features of their particular objects (Chapter 3); judgements about the evaluative features of their particular objects (Chapter 5$)^{2}$; combinations of such judgements with desires (Chapter 3 ); judgements about the satisfaction status of one's desires (Chapter 3); perceptions of one's own body (Chapter 6); and either direct or indirect (quasi-) perceptions of the evaluative features of their particular objects (Chapter 6).

This is quite a list, representing in broad outline the central views of emotion currently on the market. Deonna and Teroni do a fantastic job of presenting and evaluating these views, judiciously assessing both their merits and their faults (and along the way even offering a brief defence of realism about value (Chapter 4)). Whilst it strikes me that not every one of their arguments will, ultimately, withstand sustained critical scrutiny, at the very minimum they show that each one of the dominant approaches to emotion comes with costs and owes answers to some difficult questions. I very briefly mention some of these here before moving onto focus on Deonna and Teroni's positive proposals concerning the nature of emotions, their connection to value, and the ways in which we evaluate them (Chapters 7-10).

Emotions are not, and do not constitutively depend on, judgements. The view that they are (or do), associated with the Stoics and, more recently, Solomon 2007, Lazarus 1994, and Nussbaum 2001, falls foul of a number of difficulties. The view that emotions are nonevaluative judgements can be seen to be inadequate when we note that, for any candidate judgement, it may accompany wildly differing emotions in different individuals (29). For example, the judgement

\section{2 throughout.}

${ }^{2}$ Deonna and Teroni (39, note 1) use 'belief' and 'judgement' as interchangeable. Since their primary concern is with emotion, which they construe as an episode, 'judgement' is surely the appropriate term. Without wishing to prejudge the issue of whether emotions are episodes or states, I will use 'judgement' when discussing accounts of episodic phenomena and 'belief' when discussing accounts of the non-episodic. 
that I have won a game of tiddlywinks may mean joy for me, but misery for my opponent.

The view that emotions are evaluative judgements might initially seem to fare better; after all, as suggested above, emotions seem to be constitutively connected to certain values, their formal objects. Unfortunately for this view, argue Deonna and Teroni, evaluative judgements are not sufficient for emotions (55). It is perfectly commonplace to judge a situation dangerous, yet feel no fear. One might suppose that moving to a mixed theory would help here. Perhaps emotions are complex states; combinations of judgements and desires. For example, we might suppose fear to be a complex state of judging something to be a threat whilst desiring to avoid it. Such a position seems attractive in that, according to it, emotions have a cognitive element, and are thereby evaluable as correct, and a conative element, thereby being intrinsically motivating. Once more, however, the view can be seen to be inadequate once we notice that judgements are not necessary for emotions. On a glass skywalk, one may experience fear without any temptation to judge the situation dangerous or threatening. Arguably, furthermore, to feel fear one need not even posses the concept danger, unless we are to deny that conceptually unsophisticated subjects such as infants and non-human animals can experience the emotion (55).

What of the view that emotion can be understood on the model of perceptual experience? Such a view, one might think, is on the right track, since we think of perceptual states as non-conceptual (so shared with conceptually unsophisticated subjects), directed at objects (so intentional) and essentially conscious (so felt). ${ }^{3}$ But we can ask what are the objects of such emotional perceptions. On one view, seemingly endorsed by William James (1884), the object of an emotional state is one's own body. An emotion is the perception (from the inside) of the bodily changes caused in one by some perceived object. Whether or not this was really James' view, one of the familiar objections to it is that it does not really tell us what is distinctive about emotion per se (65). There are many situations in which one perceives a bodily change, but is not in an emotional state.

${ }^{3}$ Putting aside the supposed cases of non-conscious perception found in blindsight and masked priming. 
What then is it that all the emotional perceptions of bodily changes have in common? We are none the wiser.

Perhaps a more intuitive thought is that emotions are (analogous to) evaluative perceptions of outer objects (de Sousa 1987). Thus, fear is the perception of some object as threatening; anger the perception of some object as offensive, etc. The central problem with this view, as Deonna and Teroni see it, is that an emotion, unlike a perceptual experience, depends on a 'cognitive base' (5) that, when things go well, provides a justificatory reason for it (Chapter 8 ). Thus, my feeling angry at Bert depends on my having some awareness of Bert that, if my anger is justified, presents him as in some way deserving of my anger. This is brought out by the fact that we ask, and demand answers to, 'Why?' questions directed at the emotions. If I am angry with Bert, it is legitimate to ask why. If I am unable to provide an answer, my anger will appear unjustified. In this regard, emotion is like belief and, perhaps to a lesser extent, desire. We demand that people be able to say why they believe that $P$; we are somewhat less strict with desire. Perceptual states, like states of knowing, do not admit of such questions. To ask why I know or perceive something is to express confusion. Insofar as such questions make sense, they ask not for reasons but for causal explanations. Such is the case with perceptual experience. Thus, if asked why I am currently experiencing a ringing sound, I may answer that my alarm is sounding, or that I have been listening to loud music. But neither of these answers justifies my experiencing a ringing sound. They explain it. On the other hand, if asked why I am afraid of the spider, I may reply that it is poisonous. This places my fear within the realm of reasons, staking for it a claim to justification. This disanalogy with perceptual experience is sufficient to cast serious doubt on the perceptual account of emotional feeling, the rejection of which paves the way for Deonna and Teroni's own "Attitudinal Theory".

\section{4}

The Attitudinal Theory combines two key claims: (AT1) Evaluation is an element of the attitude, not the content, of an emotion; (AT2) Emotions are constitutively tied to states of bodily "action readiness". These two claims provide the material for Deonna and Teroni's pro- 
posed account of emotional correctness. In summary,

each emotion consists in a specific felt bodily stance towards objects or situations, which is correct or incorrect as a function of whether or not these objects and situations exemplify the relevant evaluative property (89)

This, taken together with the account of emotional justification presented in Chapter 8, constitutes the heart of the book's positive proposal concerning the nature of emotion.

To see what Deonna and Teroni have in mind with their claim that evaluation is an element of the attitude of emotion consider the case of belief (76-7). In believing that grass is green, I hold an attitude toward the content grass is green. That attitude might be characterised as considering true. It is because I hold the considering true attitude to the proposition that grass is green that my belief is correct if and only if it is true that grass is green. Truth is an element of the attitude of belief not, or not usually, its content. That is, we do not suppose that the content of the above belief is grass is green is true. Now, consider the case of emotion. A number of contemporary views place evaluative concepts in the emotion's content. Thus, grief is the judgement that someone or thing is a great loss, fear is the perception of something or someone as a threat, and so on.

This, argue Deonna and Teroni is a mistake. Just as truth, which they claim to be the formal object of belief, is not thereby an element of the content of belief, and the good, arguably the formal object of desire, is not thereby an element of the content of desire, so we should agree that the evaluative properties that are the formal objects of the various emotions are not thereby elements of the contents of emotion. Rather, we need to think of these evaluative properties as elements of the attitude one holds toward the content of an emotion.

This move, one of the more interesting innovations in the book, requires us to elaborate on the nature of emotional attitudes. If belief is considering true, what are emotional attitudes? It is at this point that Deonna and Teroni bring in the notion of felt bodily action readiness. Deonna and Teroni start from the idea that the phenomenology of the emotions is, at least primarily, bodily phenomenology and that there is a constitutive link between their phenomenology and their intentionality. The core of their position is that, "we should conceive of emotions as distinct types of bodily awareness, where the sub- 
ject experiences her body holistically as taking an attitude towards a certain object" (79). What it is for one's body to take an attitude towards an object is further elaborated by way of Frijda's 2007 notion of action readiness. We experience our body as poised to act in various ways with respect to some object. So, for example, in fear we experience our body as ready to "contribute to the neutralisation of what provokes the fear"; in anger we experience our body as, "prepared for active hostility", towards an object; in sadness, we experience our body as "prevented from entering into interaction" (80) with the object; and so on. This relates emotions to evaluative properties, their formal objects, in the following way: each of these attitudes is correct if and only if the object in question has the relevant property. It is correct to neutralise something if and only if it is a threat, it is correct to prepare for hostility toward something if and only if it is offensive, the formal objects of fear and anger respectively.

With this, we see how Deonna and Teroni combine their view of emotional evaluation as an element of the attitude with their account of bodily action readiness to derive an account of the correctness conditions of emotional states. To complete the picture, however, they also offer us an account of emotional justification. Given that, on Deonna and Teroni's view, emotions rest on a cognitive base, a natural view of justification would be that an emotion is justified if its cognitive base represents its object as possessing its formal object. So, for example, an experience of fear would be justified if it rests on a judgement, perception, etc. of that object as threatening. As I understand them, Deonna and Teroni accept that this natural thought may capture a sufficient condition of emotional justification, but they deny that it is necessary. As they put it,

[t]he cognitive base of an emotion then need not, and typically does not, contain an evaluative judgment or a value intuition. This is for instance the case when fear is explained by the subject's awareness of a dog with big teeth behaving erratically (96)

To find a necessary condition, we must loosen the requirement, allowing the cognitive base to represent the particular object as possessing some property that, in the context, constitutes an instance of the relevant evaluative property that figures in the emotion's correctness conditions (97). In the above example, the dog's having big teeth and behaving erratically constitutes it's being a threat. As such, 
fear is a justified response. Of course, I may have misjudged, or misperceived, the dog's behaviour. Perhaps it is not really a threat. In which case my emotion is justified but not correct.

Any view, such as Deonna and Teroni's Attitudinal Theory, that treats emotions as constitutively tied to bodily awareness (felt bodily action readiness) must be able to explain the fact that there seemingly exist subjects who lead a rich emotional life despite lacking the relevant bodily perception and active capacities (Cobos et al. 2002; cf. Cole 1995). This is a challenge that goes as far back as Cannon's 1927 challenge to James' account of emotion as a form of bodily awareness and recent defenders of neo-Jamesian views have an answer to hand (Damasio 2006; Prinz 2004). According to this view, emotional feeling may involve what Damasio terms an "as if loop", a neural surrogate for the relevant bodily states that, "help[s] us feel 'as if' we were having an emotional state" (Damasio 2006: 155). Whilst Damasio speaks of feeling "as if" one has an emotion, Prinz makes the stronger claim that despite its bodily character, emotion can exist in the absence of the relevant bodily changes (Prinz 2004: $57,72)$ and, in this judgement Deonna and Teroni concur, claiming that, on the Jamesian view, "[a]n emotion would then either consist in the veridical perception of certain bodily changes or, when such changes are not present, in the simulation of such perception" (65).

Given that Deonna and Teroni's view is one according to which emotions are a form of bodily awareness, and given that they mention no other response to this objection to bodily views, we can assume that the postulation of an "as if" loop is a part of their defence of their Attitudinal Theory. But it is far from clear that this is something to which they can simply help themselves. As we have seen, Deonna and Teroni take emotions to be conscious episodes, in their terms that they are "essentially felt" (18), with any putative cases of unconscious emotions being explained away as merely unattended, mis- or non-conceptualised, or merely dispositional (16-7). It is crucial to note, however, that the "feelings" of which Damasio speaks are not themselves conscious states. Damasio explicitly distinguishes between, 
a state of emotion, which can be triggered and executed nonconsciously; a state offeeling, which can be represented nonconsciously; and a state of feeling made conscious, i.e. known to the organism having both emotion and feeling (Damasio 2000: 37) ${ }^{4}$

At a first glance, then, one might suppose that Deonna and Teroni may not help themselves to the "as if" loop response, which apparently involves only non-conscious "feelings" and not conscious, essentially felt emotions. On reflection, however, perhaps the problem is not with Deonna and Teroni's use of the "as if" loop response, but with the response itself. For the putative counterexamples to bodily accounts of emotion are precisely cases of conscious emotion without bodily phenomenology, so it is far from obvious how a non-conscious state will play the role assigned to it.

There is some reason to suppose, then, that we must reject one of the following, (i) Conscious emotions can persist in patients without any bodily feeling, veridical or otherwise, (ii) Emotional phenomenology is bodily phenomenology. Deonna and Teroni apparently accept both and offer no way of resolving the tension. Admittedly, they do point out that the Attitudinal Theory can be divorced from the particular Jamesian interpretation that they give it (81). That is, one might accept AT1 whilst rejecting AT2. However, they themselves do not favour such an approach and it is remains an open question how one would characterise such evaluative attitudes in a non-bodily way. Nevertheless, the above worry about the viability of Jamesian views in general may push the Attitudinal Theory in that direction.

\section{6}

Setting the above worries aside, we can ask about the plausibility of the account of correctness. Here is Deonna and Teroni's account of correctness for fear,

Fear of the dog is an experience of the dog as dangerous, precisely because it consists in feeling the body's readiness to act so as to diminish the dog's likely impact on it (flight, preemptive attack, etc.), and this felt attitude is correct if and only if the dog is dangerous. (81)

${ }^{4}$ Likewise, Prinz (2004: Chapter 9) is happy to speak of unconscious emotions. 
This is a natural thought. Surely it is correct to run, etc. from an object if an only if it is threatening. But the naturalness of this thought masks a difficult question: what does 'correct' mean in this quotation? 'Correct' in this context cannot mean 'true', since running is not truth-evaluable. But in what sense is running from a threat correct?

The difficulty in providing an answer to this question is perhaps more obvious when we turn to some of Deonna and Teroni's other examples. Anger, they tell us, "is an experience of [someone] as offensive, precisely because it consists in feeling the body's readiness to act so as to retaliate one way or another, and this felt attitude is correct if and only if the person is or has been offensive." (81). Really? Jesus taught his followers that, "if anyone strikes you on the right cheek, turn the other also" (Matthew 5:39). Christians, it seems, would reject the thought that retaliation is the correct response to offense. Or consider the case of shame. This, say Deonna and Teroni, is, "the experience of oneself as degraded, precisely because it consists in feeling one's body ready to act so as to disappear into the ground or perhaps from the view of others, and this felt attitude is correct if and only if the person is degraded" (81). What is correctness here?

To the question of what correctness amounts to in Deonna and Teroni's account of fear, it is natural to answer "rational". Indeed, plausibly, it is rational to flee if one spies a threat and irrational otherwise. But such an answer is markedly less plausible in the other cases. Is it rational to prepare for retaliation when offended? It is far from obvious that it is. Is it rational to disappear into the ground when degraded? I am tempted to say that, insofar as I can make sense of the suggestion, it is not. More significant than such puzzlement, however, is the suspicion that correctness in these analyses is ultimately a matter of prudential or moral appropriateness. But these notions, so Deonna and Teroni suppose (7), are to be contrasted with correctness, as the earlier example of feeling (correct but prudentially inappropriate) fear at a pack of wolves was intended to illustrate. Without a further characterisation of the sense in which correctness is being employed in these analyses, it would seem that the Attitudinal Theory may fall into the trap of conflating it with appropriateness. 
My final critical comment on the Attitudinal Theory concerns the account of justification. Deonna and Teroni spell their account out in the following way,

An emotion is justified if, and only if, in the situation in which the subject finds herself, the properties she is (or seems to be) aware of and on which her emotion is based constitute (or would constitute) an exemplification of the evaluative property that features in the correctness conditions of the emotion she undergoes. $(97)^{5}$

I put to one side the worry that the notion of constitution (really an 'in virtue of' relation) employed here is less than transparent, especially regarding the issue of how we are to properly distinguish between the constituting properties and the "situation" (which Deonna and Teroni admit is required for even a supervenience claim to hold (96-7)). Instead, I focus on an objection that they pose to their own view but then, curiously to my mind, seemingly misinterpret in their response (98ff). As they put the objection, "[t]here seems to be an important gap between awareness of properties constituting an instance of an evaluative property and what justifies a given emotion." (98). The most powerful way of stating this objection, it seems to me, is that justification travels via content, so the non-evaluative content of the cognitive base (that the dog has big teeth) cannot justify the evaluative attitude that is the emotion (that it is dangerous). According to this principle, a representation of something as an $F$ cannot not justify one's taking it to be a $G$ in the absence of some further information (say that all $F$ s are Gs). This, it might be maintained,

\footnotetext{
${ }^{5}$ As it stands this condition may seem inappropriately insensitive to information possessed by the subject that undermines the credibility of the cognitive base. For example, if I falsely take the fierce dog to be safely chained to a wall, I would not be justified in fearing it. Or, at least, such a belief would surely affect the extent to which my fear was justified. Deonna and Teroni's account of justification is entirely "bottom-up", with justification flowing from the cognitive base alone, but there is surely some pressure to recognise top-down effects on justification; effects stemming from beliefs etc. that are relevant to the case, without themselves forming a part of the cognitive base. Since Deonna and Teroni do accept that justification can depend on the subject's beliefs (99-100), it seems reasonable that some such account of how justification can be defeated may be incorporated into their account.
} 
holds in cases where Fness constitutes Gness. It even holds in cases where Fness is identical to Gness, as the example of temperature and mean kinetic energy shows. Given this, we should be highly sceptical of the idea that being aware of something as having big teeth, even in a context in which this property constitutes being a threat, is sufficient to justify one's taking it to be a threat. Deonna and Teroni owe us an explanation of exactly where this line of thought goes wrong. ${ }^{6}$

\section{8}

Deonna and Teroni's The Emotions is an exemplary introduction to the philosophy of emotion. It skilfully leads the reader through the thicket of contemporary philosophical work on emotion in a way that is at once introductory and challenging. This is an impressive achievement. But it is also itself a significant contribution to that body of philosophical work. The Attitudinal Theory of emotion, defended in this book, is a serious contender to be ranked alongside other major theories currently available. There are, as I have tried to suggest above, some unanswered objections to which Deonna and Teroni owe responses. But a good book, especially an advanced introduction of this sort, should leave us with at least as many questions as it answers. In that way it inspires its students to dive into the issues themselves. This is precisely what Deonna and Teroni do. Theirs is an introduction that shows students in a methodical way exactly how to pursue careful, systematic and wide-ranging thinking about a difficult and absorbing topic. ${ }^{7}$

\footnotetext{
${ }^{6}$ Note that this argument does not assume that in order for one's emotion to be justified one must be aware, from the first-person perspective, of that which justifies it, or that one must take one's emotion to be appropriate (cf. the account discussed by Deonna and Teroni on pp. 100-1). Rather, it assumes merely that for an emotion, or any other state, to be justified, one must be in states (accessible or otherwise) with the right justifying content, and that this is individuated at the level of sense, not reference. Some externalists will deny even this. My point is simply to press Deonna and Teroni for some further illumination regarding exactly what the moving parts of their theory of justification might be.

${ }^{7}$ Thanks to the students in my Evaluating Emotions seminars 2011-14; to Julien Deonna, Fabrice Teroni and Ann Whittle for preventing me from making too many mistakes; and to Moritz Müller for many hours of conversation on emo-
} 
Joel Smith

Philosophy, School of Social Sciences

University of Manchester

Manchester, M13 9PL

joel.smith@manchester.ac.uk

\section{References}

Cannon, W. B. 1927. The James-Lange Theory of Emotions: A Critical Examination and an Alternative Theory. The American Journal of Psychology 39: 106-24.

Cobos, P., M. Sánchez, C. Garcia, M. Nieves Vera, and J. Vila. 2002. Revisiting the James versus Cannon Debate on Emotion: Startle and Autonomic Modulation in Patients with Spinal Cord Injuries. Biological Psychology 61 (3): 251-69.

Cole, J. 1995. Pride and the Daily Marathon. Cambridge, MA: MIT Press.

Damasio, A. R. 2000. The Feeling of What Happens: Body, Emotion and the Making of Consciousness. London: Random House.

Damasio, A. 2006. Descartes Error: Emotion, Reason and the Human Brain. London: Random House.

De Sousa, R. 1987. The Rationality of Emotion. Cambridge, MA: MIT Press.

Deonna, J., and F. Teroni. 2012. The Emotions: A Philosophical Introduction. London: Routledge.

Frijda, N. 2007. The Laws of Emotion. Mahwah, NJ: Lawrence Erlbaum Associates. James, W. 1884. What Is an Emotion? Mind 9: 188-205.

Kenny, A. 1963. Action, Emotion and Will. London: Routledge \& Kegan Paul.

Lazarus, R. 1994. Emotion and Adaptation. Oxford: Oxford University Press.

Nussbaum, M. 2001. Upheavals of Thought: The Intelligence of Emotions. Cambridge: Cambridge University Press.

Prinz, J. 2004. Gut Reactions: A Perceptual Theory of Emotion. Philosophy of Mind Series. Oxford: Oxford University Press.

Solomon, R. C. 2007. True to Our Feelings. New York: Oxford University Press, USA.

tional experience. I wrote this critical review while on research leave funded by the Arts and Humanities Research Council as a part of the Knowledge of Emotion project. 